Article

\title{
Use of Insulated Covers over Product Crates to Reduce Losses in Amaranth during Shipping Delays
}

\section{Lizanne Wheeler ${ }^{1}$, Lisa Kitinoja ${ }^{1}$ and Diane M. Barrett ${ }^{1,2, *}$}

1 The Postharvest Education Foundation, P.O. Box 38, La Pine, OR 97739, USA; E-Mails: lizanne@sonorapacific.com (L.W.); kitinoja@postharvest.org (L.K.)

2 Department of Food Science and Technology, University of California, 1 Shields Avenue, Davis, CA 95616, USA

* Author to whom correspondence should be addressed; E-Mail: dmbarrett@ucdavis.edu; Tel.: +1-530-752-4800; Fax: +1-530-752-0382.

Academic Editors: Michael Blanke

Received: 19 August 2015 / Accepted: 26 November 2015 / Published: 4 December 2015

\begin{abstract}
Amaranth is a leafy vegetable with high nutrient content which is sensitive to temperature and low relative humidity. Delays in shipment to market may result in significant losses, therefore improved packaging to minimize mechanical damage and reduce moisture loss are desirable. Amaranth was stored in three types of consumer packages, bunches, clamshells and thin plastic bags, within vented plastic crates. Pallet loads were either covered with insulated material or not, while awaiting transportation. Results indicated covering pallets improved the color and overall quality while reducing weight loss and wilting. Covered crates had a "good" (7.6/9.0) overall quality while uncovered averaged 5.5/9.0 or "moderate" quality. There were significant differences in consumer package type, with the bagged amaranth having almost "excellent" quality (8.8/9.0) compared to "good-fair" quality in clamshells (6.2/9.0) and "poor-fair" quality in the control bunches (4.7/9.0). Amaranth stored in thin plastic bags was better in quality and color, with less weight loss and wilting, however, temperatures at the end of six hours of storage were higher and this may lead to microbial growth. Storage of amaranth in thin bags or clamshell packages, within plastic crates covered with insulated pallet covers while awaiting shipping resulted in improved overall quality and color.
\end{abstract}

Keywords: insulated covers; clamshell packages; plastic bags; amaranth; postharvest losses 


\section{Introduction}

Leafy green vegetables, such as amaranth, are rich sources of $\beta$-carotene, ascorbic acid, riboflavin, folic acid, calcium and iron, however, they are often overlooked in the diet [1]. Leafy vegetable quality is judged based primarily on appearance and other factors that are more difficult to discern, such as tenderness, freshness and taste [2]. Appearance factors important in leafy vegetables include their shape, size, maturity, color, turgidity or degree of wilting and freedom from defects. Acedo (2010) states that weight loss and wilting, senescence-associated yellowing or browning, mechanical damage and decay are all indicators of a loss in quality [2]. Because leafy vegetables are typically over $90 \%$ water, transpiration causes the loss of water, which results in both wilting and weight loss, hence economic loss. Kanlayanarat (2007) found that a loss of just 5\%-10\% water made leafy vegetables appear wilted and unusable [3]. The optimal storage conditions for leafy greens are as close to $0{ }^{\circ} \mathrm{C}$ as possible, and at this temperature and a relative humidity of $95 \%$, they can be stored for 10-14 days [3]. According to a survey of African leafy vegetables, the average price per $\mathrm{kg}$ of amaranth in Tanzania is 667 Tanzanian shillings or $\$ 0.42$ [4].

Packages may be used for both transportation and/or point of sale (consumer packages), and they are useful in prevention or reduction of physical injury, providing ventilation to hasten cooling and escape of heat caused by respiration, and in reduction of water loss [5]. For purposes of transportation, woven baskets made of bamboo or rattan, cardboard or Styrofoam boxes and wooden or plastic crates are common means of transporting leafy vegetables [2]. Plastic crates have been found to protect produce better, and if their return and reuse can be guaranteed they may successfully reduce postharvest losses and improve safety [6]. Fernando (2006) found that, in Sri Lanka, replacement of poly sacks with plastic crates reduced losses from 30\% (poly sacks) to 5\% (plastic crates) [7]. In a study of packaging types used in Sub-Saharan Africa and India, Kitinoja and AlHassan (2012) determined that $46 \%$ of crops were packed in (too) large sacks or cloth bundles, $31 \%$ were packed in open baskets and $8 \%$ had no package at all [8]. Only $15 \%$ of crops were packaged in plastic crates, and mechanical damage and subsequent weight loss due to poor packaging was extensive.

There are very few studies on the effects of simple changes in consumer packages and/or use of insulated covers over pallets of crates of packaged produce on the reduction of loss and improvement of quality of leafy green vegetables. In the case of shipping delays, it may be even more important to cover pre-cooled plastic crates with insulating materials, and to package leafy vegetables such as amaranth in separate consumer packages. Kitinoja and AlHassan (2012) found that the percent damage due to delays in the time it takes to market were high [8]. Delays were caused by middlemen not arriving at prescribed times and other reasons. They measured losses due to physical damage in delicate crops in poor quality packages $(34.3 \% \pm 40.3 \%$ on farm, $36.4 \% \pm 35.9 \%$ at wholesale and $73.8 \% \pm 26.0 \%$ at retail markets for leafy greens in Benin) and in unpackaged crops $(8.5 \% \pm 12.7 \%$ on farm, $19.0 \% \pm 18.4 \%$ at wholesale and $22.0 \% \pm 14.4 \%$ at retail markets for bananas in Rwanda).

In one of few published studies on the effects of packaging on improved storage, Weinberger and Acedo (2011) compared the use of either a $25 \mathrm{~kg}$ carton box or grid-polystyrene crates, both with and without paper shreds as cushioning materials, for tomatoes in Vietnam [9]. These authors found that the crates with paper shreds reduced physical damage from between $11 \%-18 \%$, depending on the 
tomato maturity and cultivar, as compared to carton boxes. This resulted in a net return of between 0.02 and $0.05 \mathrm{USD} / \mathrm{kg}$, therefore creating a monetary incentive to adapt this improved technology.

Low density polyethylene (LDPE) film is often used as a consumer package for fresh leafy vegetables because of its high water permeability [10]. LDPE can also be sealed easily, has good $\mathrm{O}_{2}$ and $\mathrm{CO}_{2}$ permeability, low temperature durability, good tear resistance, and good appearance [2]. Acedo et al. (2012) conducted two studies on use of various postharvest technologies, including polyethylene bags, on storage of leafy and fruit vegetables in Cambodia, Laos, and Vietnam from 2005-2010 [11]. These authors found that storing leafy vegetables in plastic bags reduced weight loss and extended shelf life, but care had to be taken that products were washed well prior to packaging, otherwise the high humidity environment encouraged microbial growth. Studies by O'Hare et al. (2001) determined that plastic film packaging reduced both moisture loss and wilting, and was more effective than misting leaves with an anti-transpirant chemical [12].

In the current study, amaranth was chosen as the target commodity due to its prevalence in the diet in many countries, and to its temperature sensitivity. Berinyuy and Fontem (2011) found, for example, that average postharvest losses of amaranth encountered by retailers at urban markets in Cameroon averaged between $6.5 \%$ and $14.0 \%$ [13]. The objectives of this study were to answer the following research questions:

- Can low cost insulated covers maintain cool morning temperatures and reduce losses due to shipping delays?

- Does the use of consumer packages affect the maintenance of temperature and reduce losses during shipping with or without insulated covers?

\section{Experimental}

\subsection{Raw Materials}

Bunches of healthy, consistently sized local amaranth were harvested in the early morning to take advantage of cooler temperatures and randomly placed into returnable plastic crates (RPC) by the same grower on each of the three trial days in Arusha, Tanzania. The amaranth was immediately taken to the Postharvest Training and Services Center (PTSC), located approx. 10 min away, at the Asian Vegetable Research and Development Center (AVRDC), in Arusha, Tanzania. The entire harvest and storage trial was repeated on three separate days, 25 and 26 February and 5 March 2014.

\subsection{Packaging}

Each bunch of amaranth leaves was randomly divided into 3 equal parts, which were placed into three different consumer packages: (1) clear recyclable pre-formed PET clamshells (hold up to 3 lbs. strawberries); (2) very thin high density polyethylene plastic bags (Pull-N-Pak ${ }^{\circledR}$ Produce Bag, Crown Poly, Inc., Huntington Park, CA, USA); or (3) traditional bunches tied with string (control). Forty-eight containers of each of the three consumer packages were filled with amaranth leaves. Then the consumer packages were placed into the medium sized plastic returnable plastic containers (RPC) which were $54 \mathrm{~cm}$ long $\times 35.4 \mathrm{~cm}$ wide $\times 27.5 \mathrm{~cm}$ deep and had venting on all sides and the bottom . Each RPC held 4 of each type of consumer packages, as pictured in Figure 1, for a total of 
12 consumer packages per RPC. The arrangement of these consumer containers was the same in each RPC.

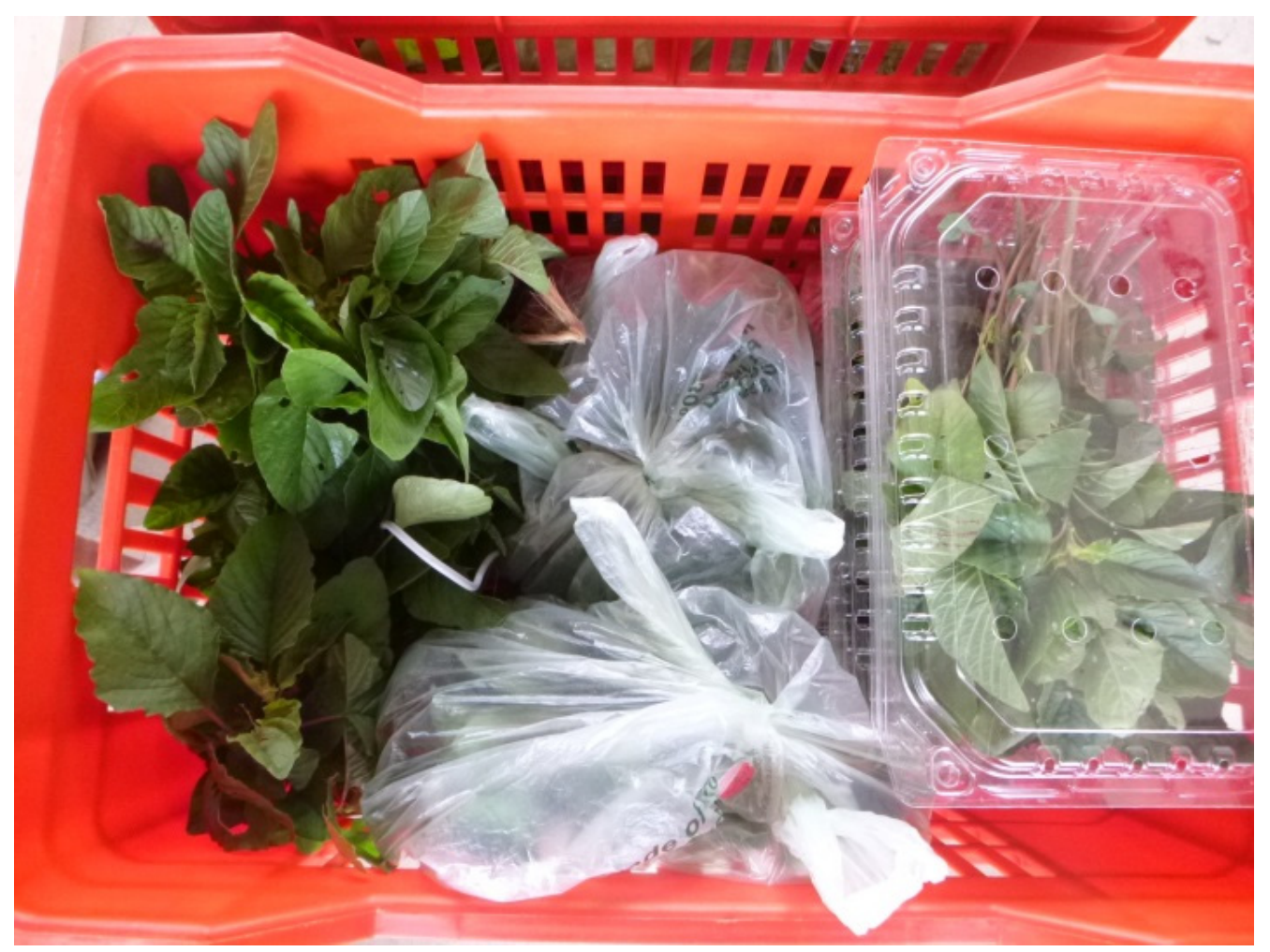

Figure 1. Arrangement of four replicates of three different consumer containers (left to right: bunches, plastic bags and clamshells) in each returnable plastic crate.

Eight crates were filled with 12 consumer packages each, for a total of 96 containers. Although it was intended to pre-cool the crates, which would have improved temperature control, it was not possible to do so in this study. The eight crates were randomly divided into two groups of four crates, and placed on wooden pallets on the concrete floor of the fenced (metal cyclone) Postharvest Training $\&$ Services Center. One pallet was covered with a Reflectix ${ }^{\mathrm{TM}}$ insulation material (Reflectix ${ }^{\mathrm{TM}}$ Inc., Markleville, IN, USA) and one remained uncovered (control or traditional pallet). Reflectix ${ }^{\mathrm{TM}}$ BP24025 bubble pack insulation consists of seven layers, two outer layers of $96 \%$ reflective aluminum foil to reflect heat, bonded to two tough layers of heavy gauge polyethylene (nominal thickness 5/16 or $0.8 \mathrm{~cm}$ ) for strength and two inner layers of bubble pack which resist heat flow, and a center layer of polyethylene for additional strength. A single layer of insulation material has an $R$-value of 6 .

The Reflectix ${ }^{\mathrm{TM}}$ cover was fitted such that it closely covered the crates, and extended over the pallet sides and along the bottom of the pallet. The bottom sides of the Reflectix ${ }^{\mathrm{TM}}$ were weighed down to keep the cover in place and tight around the crates. A piece of Reflectix ${ }^{\mathrm{TM}}$ was also sandwiched between the top and bottom layers of the wood slats of the pallet to insure that the entire crate was surrounded by Reflectix ${ }^{\mathrm{TM}}$ and there was no air movement either in or out. The wood slats on the top, that contacted the crates, were not covered with Relectix so that the crates were supported without ripping/rubbing the insulation. The stacking pattern was two crates side-by-side in a $2 \times 2$ pattern with crates numbered one through four, on a wooden pallet, as pictured in Figure 2. 


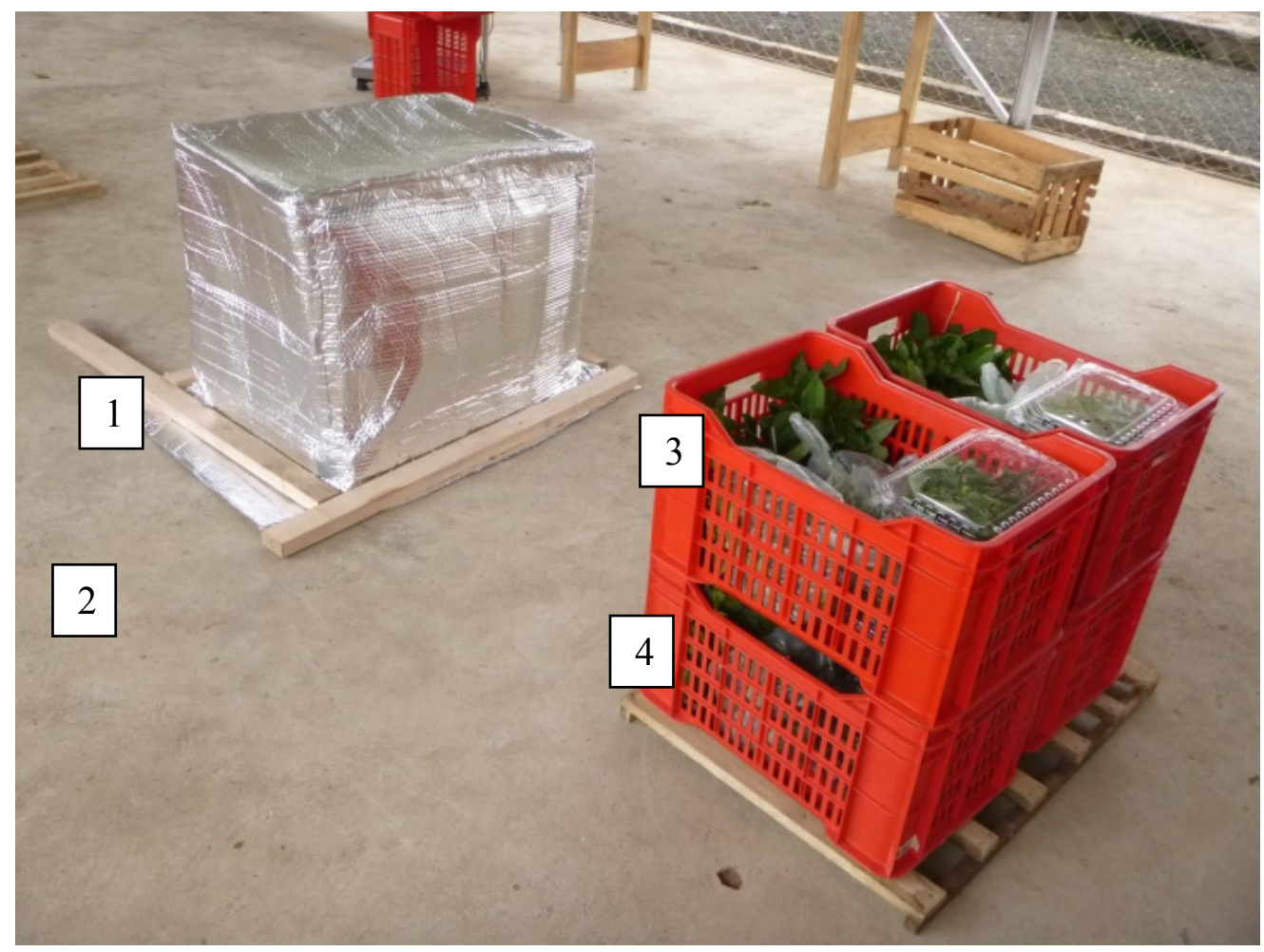

Figure 2. Stacking pattern for uncovered (right) and covered (left) returnable plastic crates placed on wooden pallets, with crates numbered one through four.

\subsection{Temperature and Relative Humidity Monitoring}

Temperature and relative humidity were measured in a number of ways. Ambient temperature and relative humidity, temperature and relative humidity within a stored clamshell package, as well as temperature at the top and bottom of covered and uncovered pallets were all documented. In addition, amaranth pulp (or leaf) temperature was measured at the beginning and end of storage.

Temperature and relative humidity were measured continuously throughout the six-hour storage period in one randomly selected clamshell package (same location in both covered and uncovered pallets) using a HOBO data logger (Onset Computer Corporation, Bourne, MA, USA). Ambient temperature and relative humidity were also recorded continuously during the first two trial days, 25 and 26 February 2014. PakSense (Boise, ID) TW30D-PAKOO 30 day temperature labels (Boise, Idaho, USA) were placed at the bottom of each pallet, as well as under the top cover of the covered pallet. Unfortunately, the label at the bottom of the uncovered pallet did not function properly, therefore these data were not collected. PakSense labels were set to sample temperature every five minutes, were encased in waterproof food-safe packaging material and readings were downloaded via a PakSense Reader (Boise, Idaho, USA). A summary of the temperature and relative humidity measurements appears in Table 1 and Figure 3. 
Table 1. Summary of temperature and relative humidity measurements in consumer packages and stacked crates in covered and uncovered pallets during six hours storage under ambient conditions.

\begin{tabular}{ccccc}
\hline Pallet Type & $\begin{array}{c}\text { Crate Number or } \\
\text { Location }\end{array}$ & $\begin{array}{c}\text { Consumer } \\
\text { Package Type }\end{array}$ & Sensor Type & $\begin{array}{c}\text { Temperature (T) and/or } \\
\text { Relative Humidity (RH) }\end{array}$ \\
\hline Ambient & & & T/RH \\
\hline \multirow{2}{*}{ Covered } & 3 & clamshell \#3 & Hobo & T/RH \\
\cline { 2 - 5 } & bottom of pallet & & PakSense & $\mathrm{T}$ \\
\cline { 2 - 5 } & under top cover & & PakSense & $\mathrm{T}$ \\
\hline Uncovered & 3 & clamshell \#3 & Hobo & $\mathrm{T} / \mathrm{RH}$ \\
\hline
\end{tabular}
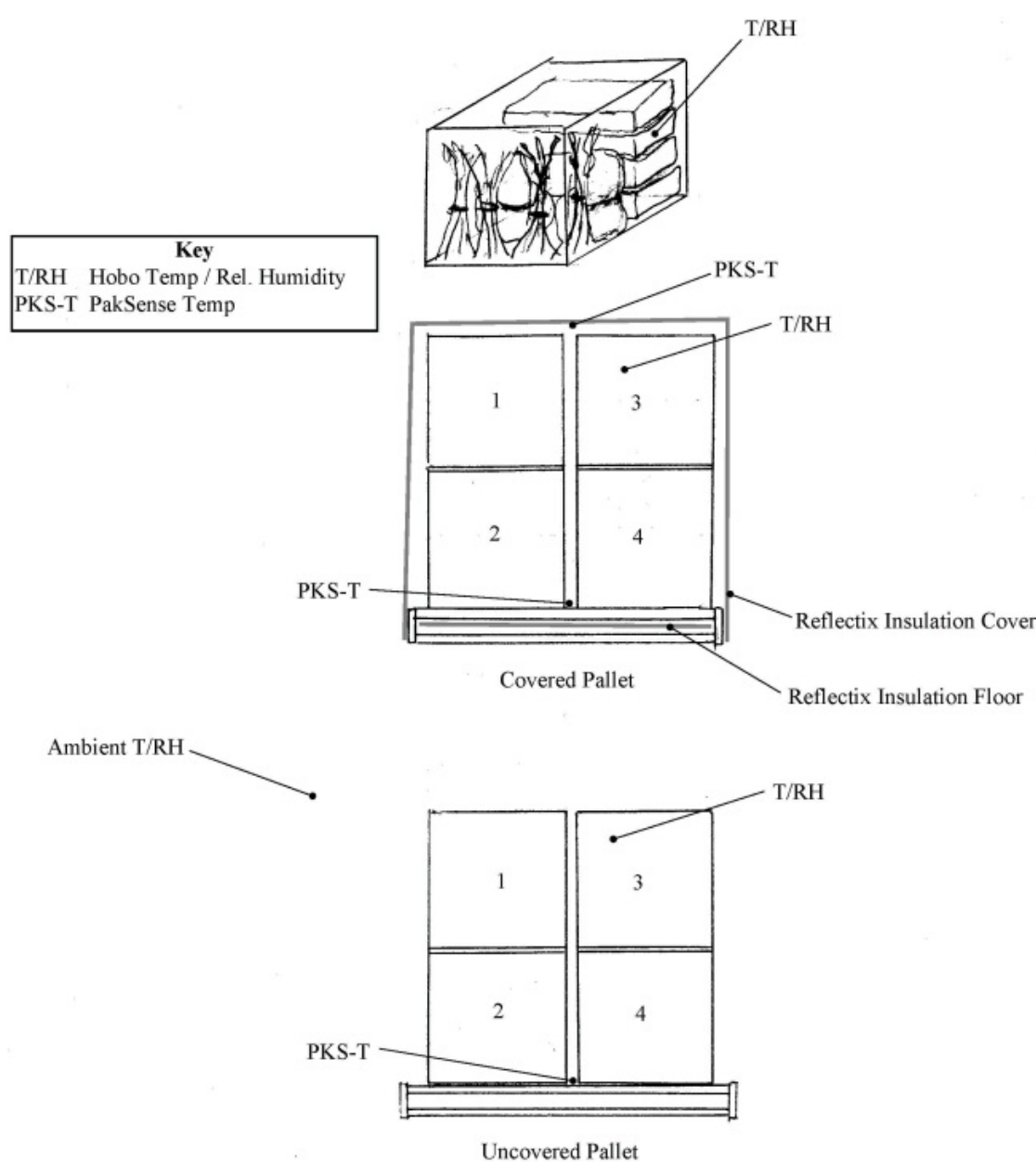

Temperature Monitoring Locations

Figure 3. Temperature and relative humidity monitoring locations in both covered and uncovered pallets of amaranth.

\subsection{Storage}

Crates were stored at ambient temperature for six hours. The entire $6 \mathrm{~h}$ storage trial was repeated on three separate days, 25 and 26 February and 5 March 2014. 


\subsection{Quality Measurements}

Initial weight of each returnable plastic crate was measured at the start of the experiment and after six hours of storage. Individual packages of amaranth were evaluated for color, overall quality and degree of wilting at the onset of the experiment and after six hours of storage at ambient temperature. Three of the four replicate consumer packages in each crate were measured. The following rating scales (Tables 2, 3 and 4), developed by the Postharvest Technology Center at the University of California, Davis, were utilized [14].

Table 2. Rating scale for the color of green vegetables.

\begin{tabular}{cc}
\hline Score & Description \\
\hline 1 & Dark-green \\
2 & Light-green \\
3 & Yellowish-green \\
4 & Greenish-yellow \\
5 & Yellow \\
\hline
\end{tabular}

Table 3. Rating scale for overall visual quality of produce.

\begin{tabular}{ccc}
\hline Score & Rating & Description \\
\hline 9 & Excellent & Essentially no symptoms of deterioration \\
7 & Good & Minor symptoms of deterioration, but objectionable \\
5 & Fair & Deterioration evident, but not serious, limit of saleability \\
3 & Poor & Serious deterioration, limit of usability \\
1 & Extremely poor & Not usable \\
\hline
\end{tabular}

Table 4. Rating scale for the wilting of green vegetables.

\begin{tabular}{cc}
\hline Score & Wilting Description \\
\hline 1 & None \\
3 & Slight, not objectionable \\
5 & Moderate, becoming objectionable \\
7 & Severe, definitely objectionable \\
9 & Extreme, not acceptable under normal conditions \\
\hline
\end{tabular}

\subsection{Statistical Analysis}

All statistical analysis was carried out using SAS (Statistical Analysis Software, Cary, NC, USA) and a Student's $t$-Test was used where applicable. All analysis was performed with $\alpha=0.05$. Results were plotted using box-and-whisker plots, which indicate mean, range and variability outside the upper and lower quartiles. 


\section{Results and Discussion}

\subsection{Overall Results}

In this study, amaranth was randomly placed in one of three consumer packages (clamshell, plastic bag or bunches) and four of each of these consumer packages were placed in a plastic crate. Four replicate plastic crates were stored on a wooden pallet, which was either uncovered (control) or covered on all sides and bottom with a Reflectix ${ }^{\mathrm{TM}}$ insulated cover. The entire $6 \mathrm{~h}$ storage trial was repeated on three separate days and measurements were made of temperature, relative humidity, weight, color, overall quality and degree of wilting. The overall results of the statistical analysis are presented in Table 5, and individual results are discussed in greater detail below. As summarized in Table 5, the pulp temperature of amaranth during storage was significantly affected by consumer package type, crate number and storage trial day. Having the pallet covered or not, and the type of consumer package significantly affected amaranth weight loss, color, degree of wilting and overall quality. The crate location in the pallet affected amaranth color and quality. There were no differences in any parameter between the three replicate containers of each consumer package, but the particular day that the trial was carried out on significantly affected every parameter except weight loss.

Table 5. Results of overall statistical analysis on effects of consumer package type and pallet cover on amaranth temperature, weight, color, overall quality and degree of wilting during six hours of storage at ambient temperature.

\begin{tabular}{ccccccc}
\hline & Treatments & Amaranth Temperature & Weight Loss & Color & Wilting & Overall Quality \\
\hline Cover & 2 & NS & S & S & S & S \\
Package & 3 & S & S & S & S & S \\
Crate & 4 & S & NS & S & NS & S \\
Replicate & 3 & NS & NS & NS & NS & NS \\
Trial day & 3 & S & NS & S & S & S \\
\hline
\end{tabular}

S, Significant; NS, Not significant.

\subsection{Temperature and Relative Humidity}

Temperature and relative humidity were measured in a number of ways. Ambient temperature and relative humidity, temperature and relative humidity within a stored clamshell package, as well as temperature at the top and bottom of covered and uncovered pallets were all documented. In addition, amaranth pulp temperature was measured at the beginning and end of storage.

\subsubsection{Ambient Temperature and Relative Humidity}

Figure 4 illustrates the ambient daily air temperatures and RH on two of the three trial days, 25 and 26 February 2014, which were quite similar. Ambient temperature was slightly higher on the third day, 5 March 2014. On the first two days, temperatures in the early morning hours were approx. $20^{\circ} \mathrm{C}$ until about 10:00 a.m., after which they increased to a maximum of approx. $27-28{ }^{\circ} \mathrm{C}$ between 4:00-4:45 p.m. Relative humidity on the first two trial days started at approximately $80 \%$ in the early morning hours, increased to approximately $90 \%$ by 10:00 a.m., then declined to a low of approximately $50 \%$ by 
4:00-5:00 p.m. Temperatures taken with digital thermometers agreed with this data, which was acquired with Hobo datalogger sensors.

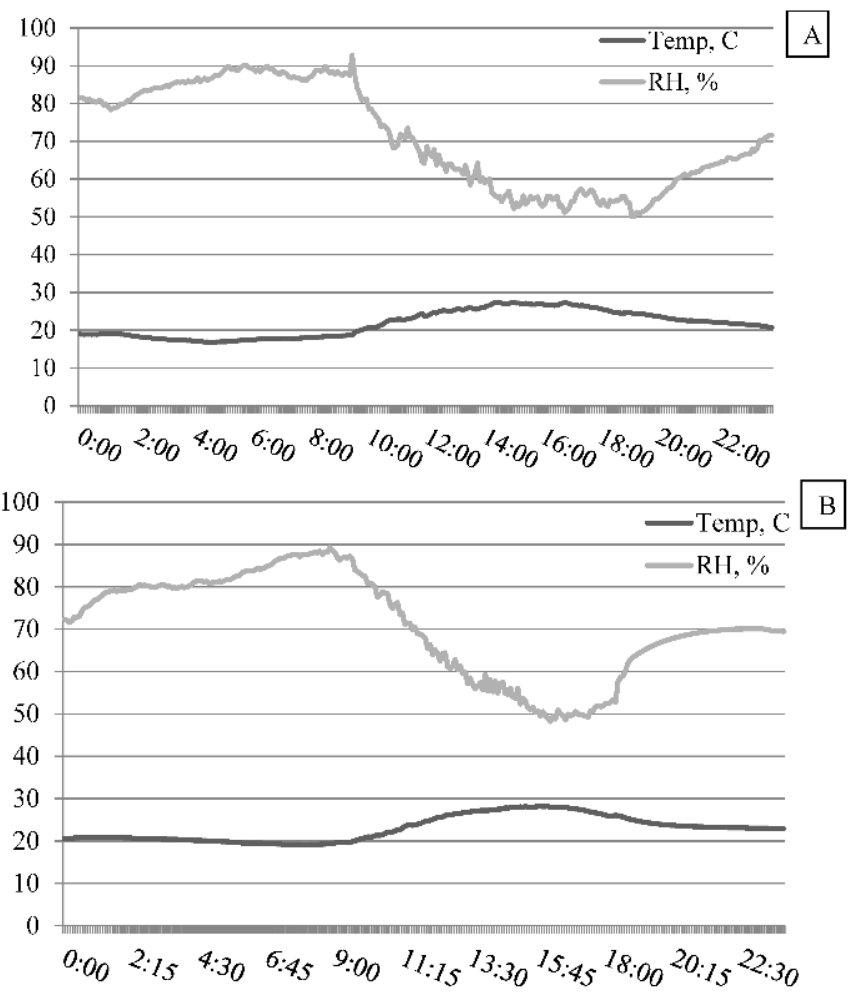

Figure 4. Daily temperature and relative humidity in Arusha, Tanzania, plotted on a $24 \mathrm{~h}$ basis on two of the trial days, (A) 25 February 2014 and (B) 26 February 2014.

\subsubsection{Temperature and Relative Humidity within Clamshell Packages}

Temperature and relative humidity inside of clamshell package \#3, within the covered and uncovered pallets, was followed continuously during the $6 \mathrm{~h}$ storage using Hobo sensors. An example plot from 25 February 2014 is presented in Figure 5. Internal temperature within the clamshell increased during storage from approx. $19-20{ }^{\circ} \mathrm{C}$ at the beginning of storage to approx. $22-23{ }^{\circ} \mathrm{C}$ at the end of storage in clamshells stored in uncovered pallets, and to $24-26^{\circ} \mathrm{C}$ in those stored in covered pallets. Although there appeared to be a slight difference in temperature related to the presence of a cover or not, this difference was not statistically significant. Relative humidity in clamshells stored in both covered and uncovered pallets increased to approximately $100 \%$ within one hour of storage and remained at a high level for the entire storage period.

Yadav and Sehgal (1995) evaluated the ascorbic acid and $\beta$-carotene content in fresh amaranth that was stored under either refrigeration $\left(4{ }^{\circ} \mathrm{C}\right)$ or ambient $\left(30^{\circ} \mathrm{C}\right)$ temperatures in India [1]. Amaranth was either packaged in polyethylene bags or not, and storage was for either 24 or $48 \mathrm{~h}$. Ascorbic acid content declined 55.3 and $65.9 \%$ in amaranth stored at $30{ }^{\circ} \mathrm{C}$ in polyethylene bags for 24 and $48 \mathrm{~h}$, respectively, from an initial concentration of $629.0 \mathrm{mg} / 100 \mathrm{~g}$ in the fresh product. Reduction in refrigerated storage, while significant, was only 2.4 and $3.3 \%$ in packaged amaranth after 24 and $48 \mathrm{~h}$, respectively. The use of packaging in polyethylene bags as compared to the control unpackaged storage also reduced losses over both 24 and $48 \mathrm{~h}$. 

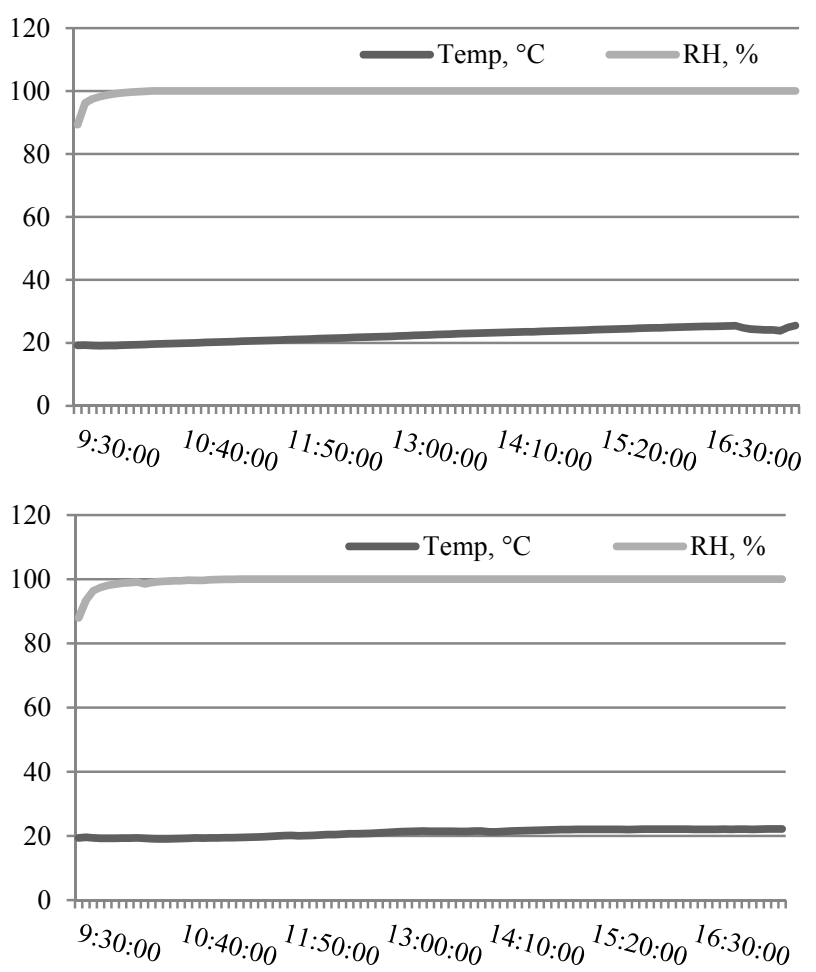

Figure 5. Internal air temperature and relative humidity within clamshell package \#3 stored in the same location within a covered (A) and uncovered (B) pallet on 25 February 2014.

\subsubsection{Temperature at the Top and Bottom of Pallets}

The PakSense sensors affixed to the top and bottom of the covered pallet were set to record temperature every five minutes and the example from 26 February 2014 (Figure 6) illustrates that temperatures at the top of the pallet were slightly lower throughout storage than those at the bottom of the pallet. In both locations, the temperature went down during the day, and remained lower than the ambient air temperature (Figure 4).

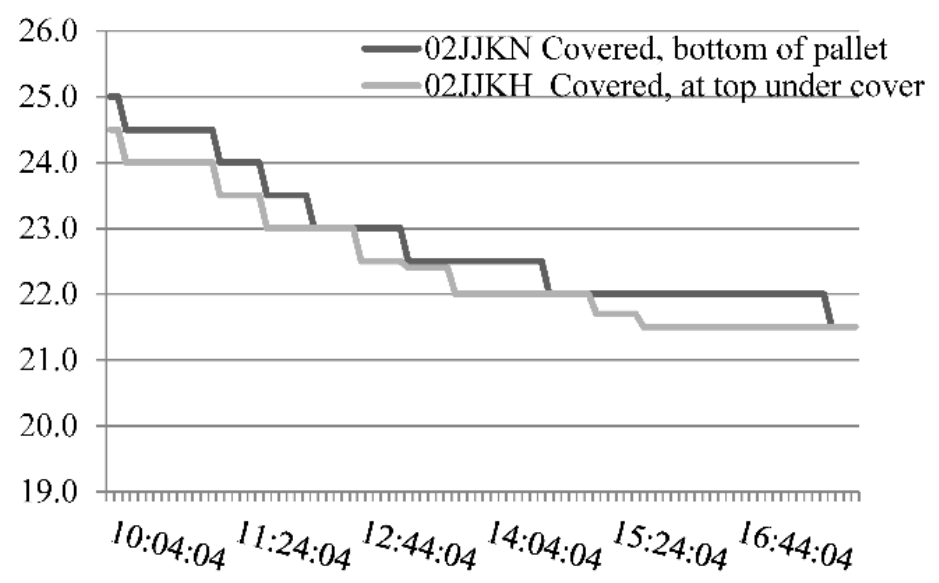

Figure 6. Temperatures at the top and bottom of the covered pallet of stored amaranth over a $6 \mathrm{~h}$ period on 26 February 2014. 


\subsubsection{Pulp Temperature of Amaranth}

There was no significant difference in final temperature of amaranth stored in crates with a pallet cover over them or not (Table 5) however the package type did make a significant difference in the internal pulp temperature within the package. Amaranth stored in plastic bags had the greatest increase in temperature from the beginning (initial temperature $\left.19-20^{\circ} \mathrm{C}\right)$ to the end of the trial $\left(6.5^{\circ} \mathrm{C}\right.$ increase on average, to final temperature of approximately $\left.26^{\circ} \mathrm{C}\right)$, followed by that stored in clamshells $\left(4.9^{\circ} \mathrm{C}\right.$ increase, for a final temperature of approximately $\left.24.5{ }^{\circ} \mathrm{C}\right)$ and then the control bunches $\left(3.7^{\circ} \mathrm{C}\right.$ increase, for a final temperature of approximately $23{ }^{\circ} \mathrm{C}$ ). All three treatments were separated significantly (Figure 7).

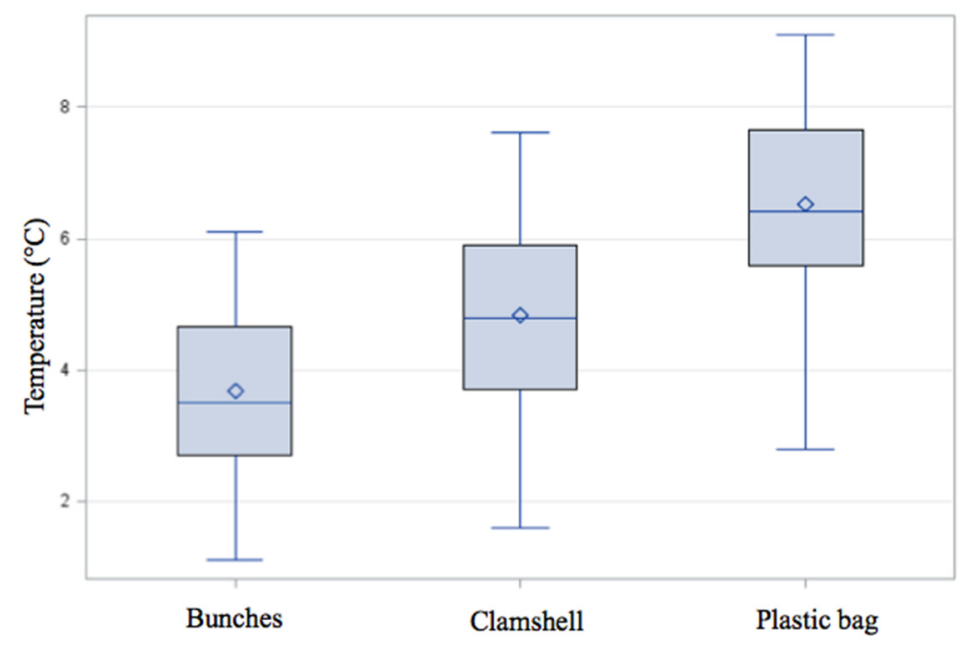

Figure 7. Increases in pulp temperature from the beginning to the end of the six-hour trial inside amaranth stored at ambient temperature in bunches (control), clamshells and plastic bags. Initial temperature at the start of the trial was approximately $19-20{ }^{\circ} \mathrm{C}$.

Thomson et al. (2001) optimized the storage conditions of 11 leafy Asian vegetables and herbs stored in various types of plastic bags, and determined that polyethylene bags in which respiration reduced the oxygen content and increased the carbon dioxide content helped reduce leaf yellowing and rot [15]. Their study involved storage for up to 15 days, therefore the time frame is different from the current study, which focuses on a $6 \mathrm{~h}$ shipping delay. Interestingly, they found that $50 \mu \mathrm{m}$ polypropylene "modified atmosphere" bags with higher oxygen permeability did not offer a benefit as compared to $50 \mu \mathrm{m}$ polypropylene "high relative humidity" bags perforated with two holes of $5 \mathrm{~mm}$ diameter. These authors also found that the optimum temperature for storage of amaranth for 15 days was between $0-4{ }^{\circ} \mathrm{C}$. Note that, in the current study, temperatures ranged from approximately $19-20{ }^{\circ} \mathrm{C}$ at harvest to $23-26^{\circ} \mathrm{C}$ at the end of $6 \mathrm{~h}$ storage, depending on the presence of an insulated cover or not and the type of consumer package used.

In a study by Kitinoja and AlHassan (2012), it was found that temperatures for leafy vegetables harvested in Rwanda and Benin were generally higher than those recommended for quality maintenance [8]. Pulp temperatures for temperate crops, including amaranth, which were handled 
without care for shading or temperature control, were found to be $25-30{ }^{\circ} \mathrm{C}$ above the recommended lowest safe handling temperatures of $0-2{ }^{\circ} \mathrm{C}$.

There was also a difference between the four crates in terms of the increase in amaranth pulp temperature during storage. Amaranth stored in crates 1 and $3\left(5.4-5.7^{\circ} \mathrm{C}\right.$ increase on average) were significantly warmer than crate $2\left(4.7^{\circ} \mathrm{C}\right)$, and crate $4\left(4.3^{\circ} \mathrm{C}\right)$ was significantly cooler than all of the other crates. As illustrated in Figure 2, crates 2 and 4 were located on the bottom of the stacks, directly on the wooden pallet, which was placed on a concrete floor. It may be that the cooler floor temperature affected the temperature in those two bottom crates. The temperature of all four crates was affected by air temperature, wind and other environment factors, in particular because the cyclone fence allowed sun and wind exposure. The PakSense labels indicated higher temperatures at the top of the covered pallet as compared to the bottom, which correlates well with the pulp temperature data indicating lower temperatures at the bottom of the pallet. Note that temperatures during the last hour of storage were approx. $21.5^{\circ} \mathrm{C} v s .22{ }^{\circ} \mathrm{C}$, which is quite similar.

As desired, there was no significant difference between the three replicate consumer packages stored within each crate. There was a significant difference in pulp temperature of the amaranth between the three trial days, as expected from the slight differences in daily temperature. Average differences in pulp temperature from the beginning of the six hour trial to the end during trials 1,3 and 2 were $5.2{ }^{\circ} \mathrm{C}, 5.0^{\circ} \mathrm{C}$ and $4.8^{\circ} \mathrm{C}$, respectively, and all three replicate trials separated significantly.

\subsection{Weight Loss}

Amaranth stored in the uncovered pallet lost significantly more weight than that in the covered one (11.0\% vs. $2.7 \%$ ) during the $6 \mathrm{~h}$ storage period, indicating that the Reflectix ${ }^{\mathrm{TM}}$ cover successfully reduced the amount of moisture loss which took place from the amaranth during storage (Figure 8).

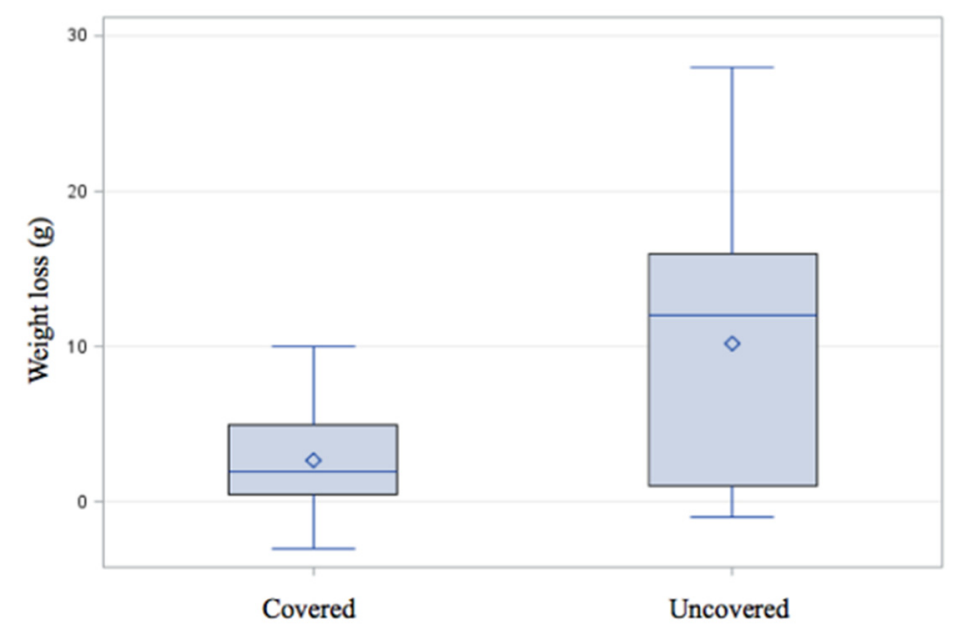

Figure 8. Weight loss in uncovered (control) and Reflectix ${ }^{\mathrm{TM}}$ covered pallets of amaranth after six hours storage at ambient temperatures.

To calculate the cost/benefits of using the Reflectix ${ }^{\mathrm{TM}}$ cover, it is possible to do a simple comparison of current practice, not using pallet covers, vs. the new practice (Table 6). Reflectix ${ }^{\mathrm{TM}}$ can be purchased at retail prices in small quantities $\left(\$ 43.00\right.$ for a 25 foot $\times 2 \mathrm{ft}$ roll; or $4.64 \mathrm{~m}^{2}$ ) or in much larger 
wholesale priced rolls ( $\$ 200.00$ per roll of $125 \mathrm{ft}$ by $4 \mathrm{ft}$; or $46.4 \mathrm{~m}^{2}$ ). The cost per square meter is largely dependent upon the size of the roll purchased, and $3 \mathrm{~m}^{2}$ are required to make one pallet cover. In this case for the cost/benefit analysis, a price of $\$ 5.00 / \mathrm{m}^{2}$ was employed since potential users are able to purchase supplies at close to wholesale prices from resource providers in Tanzania. Assumptions are that $1000 \mathrm{~kg}$ of amaranth were stored, market price was $\$ 0.42 / \mathrm{kg}$, the cover could be used at least twice, there was no difference in quality between the two practices and the losses were as determined above. Note that there was an economic advantage to using Reflectix ${ }^{\mathrm{TM}}$ covers, due to reduction of weight loss in both the first and second use. For the second and later use, profits increased substantially since the input costs were paid off during the first use.

Table 6. Costs and benefits of using Reflectix ${ }^{\mathrm{TM}}$ insulated cover over pallets during a $6 \mathrm{~h}$ holding period prior to shipping.

\begin{tabular}{|c|c|c|}
\hline $\begin{array}{l}\text { Temporary Storage } \\
\text { of } 1000 \mathrm{~kg} \text { Amaranth }\end{array}$ & Current Practice & New Practice \\
\hline Describe & Uncovered & $\begin{array}{l}\text { Cover sides and bottom of } \\
\text { pallet load with Reflectix }\end{array}$ \\
\hline \multicolumn{3}{|l|}{ Costs } \\
\hline $\begin{array}{l}\text { Reflectix }{ }^{\mathrm{TM}} \_\$ 5.00 / \mathrm{m}^{2} \times 3 \mathrm{~m}^{2} \\
2 \text { "Metal foil tape }(10 \mathrm{~m} \text { roll })\end{array}$ & & $\$ 15.00, \$ 5.00$ \\
\hline Relative costs & & $\$ 20.00$ \\
\hline Recurring costs & & 0 \\
\hline \multicolumn{3}{|l|}{ Expected Benefits } \\
\hline$\%$ Losses & $11 \%$ & $2.7 \%$ \\
\hline Amount for sale (kg) & 890 & 973 \\
\hline Price/kg ${ }^{1}$ & $\$ 0.42$ & $\$ 0.42$ \\
\hline Total market value & $\$ 373.80$ & $\$ 408.66$ \\
\hline Market value — costs & $\$ 373.80$ & $\$ 388.66$ \\
\hline Relative profit 1st load of $1000 \mathrm{~kg}$ & & $+\$ 14.86$ \\
\hline Relative profit $2 \mathrm{nd}$ load of $1000 \mathrm{~kg}$ & & $+\$ 34.86$ \\
\hline Insulated cover can be reused many & & $+\$ 34.86$ with each subsequent \\
\hline more times with mindful handling practices & & load of $1000 \mathrm{~kg}$ of amaranth \\
\hline
\end{tabular}

In addition to the advantage of using Reflectix ${ }^{\mathrm{TM}}$ covers, there was a significant difference in weight loss between the three consumer package types (Figure 9), with amaranth in the bags losing the least weight $(1.6 \%)$, followed by clamshells $(7.6 \%)$, and the control bunches losing the most weight (11.4\%). All 3 treatments separated significantly. In terms of weight loss, there was no significant difference between the four crates, the three samples within each crate, or the three replicate trial days.

Acedo et al. (2012) conducted two studies on use of various postharvest technologies, including storage in polyethylene bags, on leafy and fruit vegetables in Cambodia, Laos, and Vietnam from 2005-2010 [11]. These authors also found that storing leafy vegetables in plastic bags reduced weight loss and extended shelf life. In Vietnam, they compared the use of 25 micron bags made of either low density polyethylene bag (LDPE) or polypropylene (PP) to the common practice of storing leafy vegetables in bunches. Kangkong and Chinese kale were held for 2-3 days at ambient temperatures to simulate delays in transportation. Kangkong held in LDPE bags for three days experienced only $2 \%$ 
weight loss, compared to $22 \%$ in the controls, and the net return was an additional $0.09 \mathrm{USD} / \mathrm{kg}$. Chinese kale held in PP bags for two days experienced only 1\% weight loss, compared to 37.5\% in the control unpackaged bunches, and the additional return was $0.32 \mathrm{USD} / \mathrm{kg}$.

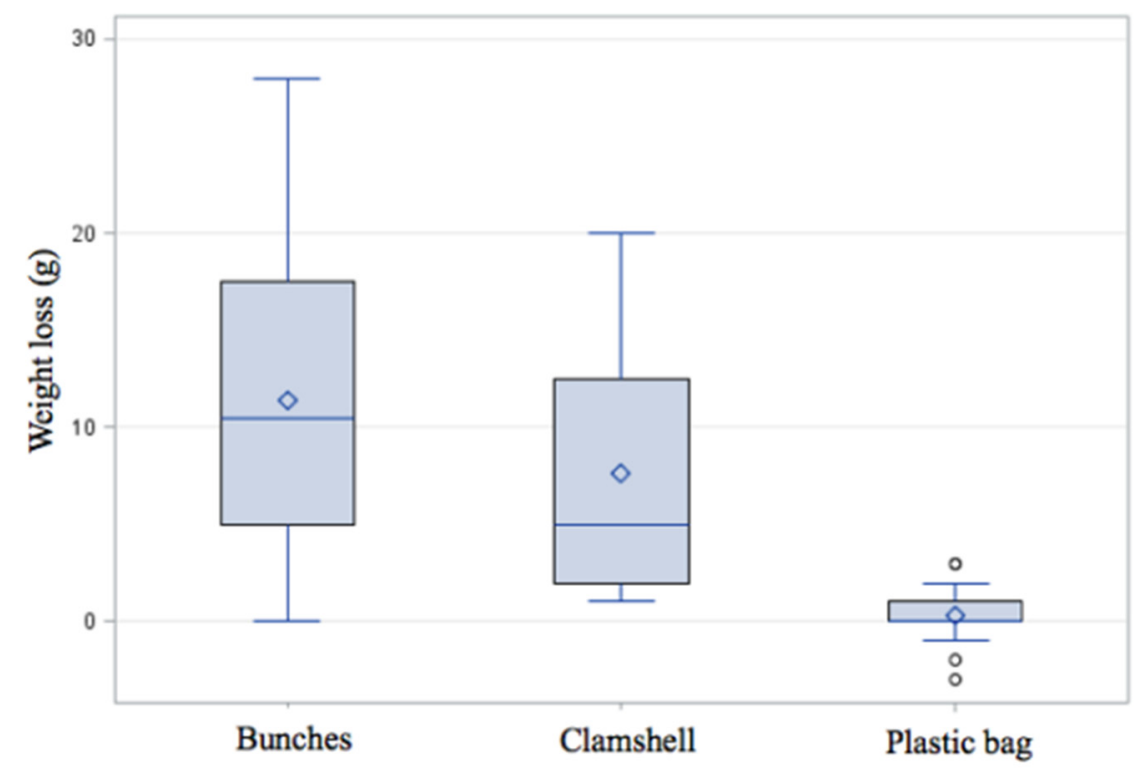

Figure 9. Weight loss in amaranth stored in bunches (control), clamshells and plastic bags during six hours storage at ambient temperatures.

O'Hare et al. (2001) found that wilting in pak choi stored unpackaged stored at $35{ }^{\circ} \mathrm{C}$ took place at a rate of $2.8 \%$ per hour [12]. Leaves with the lowest initial water potential experiment the most rapid wilting, and the highest water potential occurred in pak choi harvested at 4:00 a.m. and 10:00 p.m. These authors found that plastic film packaging reduced both moisture loss and wilting, and was more effective than misting leaves with an anti-transpirant chemical.

Prabhu and Barrett (2009) stored two leafy vegetables, Cassia tora (sicklepod) and Corchorus tridens (Jew's mallow), which were packaged in plastic bags within cardboard boxes in the dark at $20{ }^{\circ} \mathrm{C}$ for up to six days and found no significant change in moisture content [16]. This may have been due to the high humidity environment, and the absence of light which may have reduced the respiration rate in these leafy vegetables.

Negi and Roy (2004) stored amaranth in either $500 \mathrm{~g}$ bundles or the leaves were separated from petioles and $200 \mathrm{~g}$ was packaged in ventilated (0.24\%) low density polyethylene (100 gauge) bags placed in plastic crates and stored in a well ventilated room at conditions ranging from $22.0-31.5{ }^{\circ} \mathrm{C}$ and $35 \%-65 \% \mathrm{RH}$ for up to four days [17]. Moisture content decreased over time, dependent on temperature and relative humidity of the storage container. Packing the leaves in polyethylene bags was effective in decreasing the water loss.

In the study on storage of leafy vegetables conducted in Rwanda, Kitinoja and AlHassan (2012) found that mean weight loss on the farm for 10 samples of amaranth packed in sacks was $10.8 \% \pm 9.1 \%$ over up to $240 \mathrm{~min}$ directly after harvest [8]. During $6 \mathrm{~h}$ display at a retail market, the additional mean weight loss in bunches of amaranth was $11.3 \% \pm 2.8 \%$. This compares well to the $11.0 \%$ loss in weight determined in the present study during storage in uncovered plastic crates. 


\subsection{Color}

There was a significant difference between the covered and uncovered pallets in color change in the amaranth during storage, with better average color (1.3, close to dark green) in amaranth stored in the covered pallets, vs. 2.1 (light green) in that stored in the uncovered pallets. In addition, the amaranth stored in uncovered pallets had greater variability in color than the amaranth stored in covered pallets.

There was also a significant difference in color between the consumer packages, with amaranth stored in bags maintaining a consistent dark green (1.0) color in both uncovered and covered pallets (Table 7). In the amaranth stored in clamshells, there was a wide range of color averaging 1.8 (towards light green), with the uncovered bunches rated at 2 and the covered clamshells rated at 1 (dark green). There was an average color of 2.4 (light green, towards yellowish-green) in the control bunches, which represented ratings of 3 (yellow green) in the uncovered and 2 (light green) in the covered pallets. All three consumer package treatments separated statistically.

The amaranth color also differed significantly between its location in crates, with crates \#4 (bottom) and \#3 (top) averaging a better color of 1.5-1.6 (between dark and light green) and crates \#1 (top) and \#2 (bottom) averaging a less desirable 1.8 (almost light green). Looking at the location of the crates, as illustrated in Figure 2 (crates 1 and 3 on top), it may be that one side of the pallet was more exposed to sun or wind, as crate 3 was stacked on top of crate 4 .

Table 7. Influence of pallet covers and consumer packages on color, wilting and overall quality of amaranth held for six hours under ambient conditions.

\begin{tabular}{ccccc}
\hline Pallet Cover & Consumer Package & Color & Wilting & Overall Quality \\
\hline \multirow{3}{*}{ Uncovered } & Bunches & $3 \pm 0 \mathrm{a}$ & $6 \pm 1 \mathrm{a}$ & $3+1 \mathrm{e}$ \\
& Clamshells & $2 \pm 1 \mathrm{~b}$ & $5 \pm 2 \mathrm{~b}$ & $5 \pm 3 \mathrm{~d}$ \\
& Plastic bag & $1 \pm 0 \mathrm{~d}$ & $1 \pm 0 \mathrm{~d}$ & $9 \pm 0 \mathrm{a}$ \\
\hline \multirow{3}{*}{ Covered } & Bunches & $2 \pm 1 \mathrm{c}$ & $3 \pm 1 \mathrm{c}$ & $6 \pm 2 \mathrm{c}$ \\
& Clamshells & $1 \pm 0 \mathrm{~d}$ & $1 \pm 1 \mathrm{~d}$ & $8 \pm 2 \mathrm{~b}$ \\
& Plastic bag & $1 \pm 0 \mathrm{~d}$ & $1 \pm 1 \mathrm{~d}$ & $9 \pm 1 \mathrm{ab}$ \\
\hline
\end{tabular}

Different letters in the table (a, b, c, d, e, ab) are the results of the determination in section 2.6 statistical analysis.

There was no significant difference between the 3 replicate containers within each crate. The three trial days did differ; however, with amaranth color on trial \#1 on 25 February 2014 and trial \#3 on 5 March 2014 averaging 1.6, which is between dark green and light green and amaranth color on trial day \#2 was 1.8, closer to light green. As stated above, trial 1 (25 February 2014) was the warmest, followed by trial 3 (5 March 2014) and trial 2 (26 February 2014) was the coolest. This would seem to indicate that color was maintained better on the warmer trial days.

Prabhu and Barrett (2009) stored two leafy vegetables, Cassia tora (sicklepod) and Corchorus tridens (Jew's mallow), which were packaged in plastic bags within cardboard boxes in the dark at $20{ }^{\circ} \mathrm{C}$ for up to six days and found that the $\mathrm{L}$ value increased significantly over time, indicating a lightening of color [16]. In addition the $b$ value increased and the chlorophyll content decreased significantly over time, which correlated to a yellowing of the leaves due to loss of the green pigment. 


\subsection{Wilting}

Amaranth stored in covered crates experienced significantly less wilting on average (1.8, none-slight) than that stored uncovered (4.0 on average, slight-moderate), and there was also much less variability in the results of the covered crates.

There was also a significant difference between consumer packages, with the least wilting, for the most part, in amaranth stored in the bags $(1$, none), whether they were in uncovered or covered pallets (Table 7). While most of the amaranth stored in bags did not undergo wilting, there were three bags stored in the covered pallet that were significantly wilted. There was significantly more wilting in amaranth stored in clamshells, but again covering the pallets reduced this from 5 (slight-moderate) to 1 (none). The greatest amount of wilting occurred in the control bunches (on average 4.6, slight-moderate), but while wilting in uncovered pallets was high $(6$, moderate-severe), that in covered pallets was only rated 3 , slight.

There was a significant difference in the location of the crates, with the least wilting in bottom crate \#4 (2.6, slight), but there was no significant difference between that and crates \#2 (bottom) and top crate 3 (2.8-3.0). Crate \#1 (top) had a significantly higher level of wilting (3.2). It may be that any heat produced by respiration of amaranth in crates stored on the bottom of the pallet (crates \#2 and 4) rose to influence temperature and wilting in crates on the top (crates \#1 and 3). In addition, as noted with the effect of crate location on color, it may be that crates 3 and 4 were not exposed to sun and/or wind, while crates 1 and 2 were. There was no significant difference in wilting between the replicate containers in the same crate. There was a significant difference in wilting between trial day 1 (2.5, none-slight) and trial days 2 and 3 (3.1-3.2, slight).

\subsection{Overall Quality}

Covered crates had a "good" (7.6 out of 9) overall quality while uncovered averaged a significantly lower level of 5.5 or "moderate" quality. There was also more variability in quality in the uncovered crates. Acedo (2010) found that palletization reduces the number of times an individual container is handled, and reduces damage to the contents [2]. Therefore, the use of pallets most likely enhanced the overall quality in both uncovered pallets and those covered with Reflectix ${ }^{\mathrm{TM}}$.

There were significant differences in consumer package type, with the bagged amaranth having on average "excellent" quality (9) compared to "good-fair" quality in clamshells (6.2) and "poor-fair" quality in the control bunches (4.7). There was also more quality variability in clamshells. Amaranth in covered vs. uncovered clamshells had better overall quality ( $8 v s .5)$, as did that stored in covered $v s$. uncovered bags (6 vs. 3). However, the bags did not protect the amaranth from crushing and there was visual evidence of this at the end of the trial. In addition, poor gas permeability inside the bags resulted in condensation and some formation of slimy residues indicating microbial growth. While most of the amaranth stored in bags had excellent quality, there were six bags stored in the covered pallet that were significantly wilted.

Tulio et al. (2002) stored jute leaves in sealed polyethylene bags and stored these at 1, 8, 15, 20 and $30{ }^{\circ} \mathrm{C}$ until decay set in [18]. These authors found that the overall quality and freshness of the leaves declined rapidly at $30{ }^{\circ} \mathrm{C}$, and the optimal storage was at $8{ }^{\circ} \mathrm{C}$. Jute leaves stored at $8{ }^{\circ} \mathrm{C}$ were of good 
quality for eight days, but deteriorated rapidly after that. Leaves stored at $30{ }^{\circ} \mathrm{C}$ were only of good overall quality for 1-2 days.

Losses in overall quality translate to reduced income. For example, Kitinoja and AlHassan (2012) found that for amaranth in Benin, economic losses were estimated at $30 \%$, due to the reduction in market value per $\mathrm{kg}$ of the produce sold when compared to the highest price per $\mathrm{kg}$ offered for higher quality produce on the same day in that market [8].

Amaranth quality was significantly lower when stored in top crate \#1 (6.1, fair-good) and bottom crate 2 (6.4) as compared to crates top crate 3 and bottom crate 4 (6.8-7.0, good). As discussed with the color and wilting results, this may be because crates 1 and 2 were exposed to adverse environmental conditions on one side of the Postharvest Training and Services Center (Davis, California, USA). For all three quality parameters (color, wilting and overall quality), amaranth stored in crates 3 and 4 was of poorer quality than that stored in crates 1 and 2 . There was no significant difference between the three replicate containers within one crate, which is desirable. There was a significant difference between replicate trial days, with trial \#1 being significantly higher (7.2, good) in overall quality than \#2 and \#3 (both 6.2-6.3, fair-good).

\subsection{Summary}

Covering pallet sides and bottom with Reflectix ${ }^{\mathrm{TM}}$ significantly reduced weight loss in amaranth, as well as maintaining a desirable dark green color and reducing wilting. The overall quality of amaranth stored in covered pallets was significantly higher than that stored uncovered, even though Hobo sensors (Bourne, Massachusetts, USA) showed that temperatures in covered pallets were higher at the end of storage than those in uncovered pallets (approximately $23^{\circ}$ vs. $25^{\circ} \mathrm{C}$ ).

Amaranth stored in bags was generally the highest quality and had the least weight loss and wilting, with the darkest green color. However, the bags did not always protect the amaranth from crushing and there was visual evidence of this at the end of the trial. Poor gas permeability inside the bags resulted in condensation and some formation of residues that appeared to be microbial growth. An indication of the poor transmission of heat from the respiring amaranth out of the bags was the significantly greater increase in pulp temperature at the end of the trial in bags $\left(6.5^{\circ} \mathrm{C}\right)$ as compared to clamshells $\left(4.9^{\circ} \mathrm{C}\right)$ or bunches $\left(3.7^{\circ} \mathrm{C}\right)$. Although the amaranth stored in bags was of the highest quality after this $6 \mathrm{~h}$ holding trial, we suspect that additional storage would have resulted in a decline in quality. In all cases, the use of either bags or clamshells resulted in a significant improvement in weight loss, color, wilting and overall quality of stored amaranth as compared to traditional bunches. For more reliable quality over a longer storage period we suggest the use of clamshells.

There were some differences in amaranth quality that could be correlated to location of the crate within the pallet. Crates on the bottom of the pallet (\#2 and 4) had less of an increase in pulp temperature by the end of storage, we believe because they were closer to the relatively cool concrete floor. In addition, one side of the pallet where crates \# 3 and 4 were located had significantly better color, less wilting and greater overall quality. This may have resulted from less exposure to sun, air or wind.

The three replicate containers of each consumer package type within each crate did not differ significantly in any parameter tested, which is desirable. Finally, there were some significant differences between the three trial days, with day 1 (25 February 2014) having better color, less wilting, and the 
highest overall quality. There were no differences in ambient temperature, relative humidity or other factors that would explain these results.

\section{Conclusions and Recommendations}

There are economic incentives to covering plastic crates holding amaranth with insulating material during shipping delays to reduce weight loss. The use of plastic bags resulted in improved overall quality and color, and reduced wilting and weight loss, however, there was temperature build-up and condensation. Future experiments should investigate the use of very thin, vented bags. In addition, future studies should examine the use of pre-cooled plastic crates and vented bags.

\section{Acknowledgments}

The authors would like to thank Radegunda Kessy of the World Vegetable Organization for her assistance with this project. In addition we would like to thank Chukwan Techakanon for help with the statistical analysis.

\section{Author Contributions}

Lizanne Wheeler and Lisa Kitinoja planned the experiments, which were carried out by Lizanne Wheeler. Diane M. Barrett analyzed the data and wrote the manuscript, with contributions from authors Lizanne Wheeler and Lisa Kitinoja.

\section{Conflicts of Interest}

The authors declare no conflict of interest.

\section{References}

1. Yadav, S.K.; Seghal, S. Effect of home processing on ascorbic acid and $\beta$-carotene content of spinach (Spinicia oleracia) and amaranth (Amaranthus tricolor) leaves. Plant Foods Hum. Nutr. 1995, 47, 125-131.

2. Acedo, A.L. Postharvest Technology for Leafy Vegetables; AVRDC-The World Vegetable Center: Shanhua, Taiwan, 2010; p. 67.

3. Kanlayanarat, S. Postharvest technologies for fresh leafy vegetables in Thailand. In Proceeding of the Paper Presented during the RETA 6376 Workshop on Best Practices in Postharvest Management of Leafy Vegetables in GMS Countries, Hanoi, Vietnam, 25-27 October 2007; Acedo, A.L., Weinberger, K., Eds.; AVRDC-The World Vegetable Center: Shanhua, Taiwan, 2007; pp. 27-83.

4. Lotter, D. Survey of African Indigenous Vegetable (AIV) Production and Marketing in Tanzania. Available online: http://crsps.net/wp-content/uploads/2013/03/Wed-M-6-Lotter-Af-Ind-VegTZ.pdf (accessed on 6 May 2015).

5. Gast, K.L.B. Containers and Packaging Fruits \& Vegetables; Kansas State University: Manhattan, KS, USA, 1991; p. 4. 
6. Adhikari, S. Country paper: Nepal (2). In Postharvest Management of Fruit and Vegetables in the Asia-Pacific Region, Proceedings of the Conference on Reduction of Postharvest Losses of Fruit and Vegetables held in India, New Delhi, India, 5-11 October 2004; Rolle, R.S., Ed.; Asian Productivity Organization (APO): Tokyo, Japan, 2006, pp. 200-208.

7. Fernando, M.D. Country paper: Sri Lanka (2). In Postharvest Management of Fruit and Vegetables in the Asia-Pacific Region, Proceedings of the Conference on Reduction of Postharvest Losses of Fruit and Vegetables held in India, New Delhi, India, 5-11 October 2004; Rolle, R.S., Ed.; Asian Productivity Organization (APO): Tokyo, Japan, 2006; pp. 264-275.

8. Kitinoja, L.; AlHassan, H.A. Identification of appropriate postharvest technologies for improving market access and incomes for small horticultural farmers in Sub-Saharan Africa and South Asia. Part 1: Postharvest losses and quality assessments. Acta Hortic. 2012, 934, 31-40.

9. Weinberger, K.; Acedo, A.L. Development and diffusion of vegetable post-harvest and processing technologies in the Greater Mekong Subregion of Asia. In Innovative Policies and Institutions to Support Agro-Industries Development; da Silva, C.A., Nomathemba, M., Eds.; Food and Agriculture Organization of the United Nations: Rome, Italy, 2011; pp. 353-376.

10. Somjate, S. Packaging and transportation of fruits and vegetables for better marketing. In Postharvest Management of Fruit and Vegetables in the Asia-Pacific Region, Proceedings of the conference on Reduction of Postharvest Losses of Fruit and Vegetables held in India, New Delhi, India, 5-11 October 2004; Rolle, R.S., Ed.; Asian Productivity Organization (APO): Tokyo, Japan, 2006; pp. 15-22.

11. Acedo, A., Jr.; Weinberger, K.; Holmer, R.J.; d'Arros Hughes, J. Postharvest research, education and extension: AVRDC—The world vegetable center's experience. Acta Hort. (ISHS) 2012, 943, 47-61.

12. O’Hare, T.J.; Able, A.J.; Wong, L.S.; Prasad, A.; McLauchlan, R. Fresh-cut Asian vegetables-Pak choi as a model leafy vegetable. In Postharvest Handling of Fresh Vegetables, Proceedings of a Workshop Held in Beijing, Beijing, China, 9-11 May 2001; O'Hare, T., Bagshaw, J., Li, W., Johnson, G.I., Eds.; Australian Centre for International Agricultural Research: Canberra, Australia, 2001; pp. 113-115.

13. Berinyuy, J.E.; Fontem, D.A. Evaluating post harvest opportunities and constraints to utilization and marketing of African leafy vegetables in Cameroon. AJFAND Online 2011, 11, 4647-4663.

14. Kader, A.A; Cantwell, M.I. Produce Quality Rating Scales and Color Charts, 2nd ed.; University of California, Postharvest Technology Center: Davis, CA, USA, 2010; pp. 1-2.

15. Thomson, G.; Winkler, S.; Morgan, W.; Midmore, D.J.; Kleinhenz, V.; Lodge, G.; Tomkins, B. Australian studies on storage and packaging of Asian leafy vegetables, Chinese water chestnut, and kabocha pumpkin. In Postharvest Handling of Fresh Vegetables, Proceedings of a Workshop Held in Beijing, Beijing, China, 9-11 May 2001. O’Hare, T., Bagshaw, J., Li, W., Johnson, G.I., Eds.; Australian Centre for International Agricultural Research: Canberra, Australia, 2001, pp. 61-71.

16. Prabhu, S.; Barrett, D.M. Effects of storage condition and domestic cooking on the quality and nutrient content of African leafy vegetables (Cassia tora and Corchorus tridens). J. Sci. Food Agric. 2009, 89, 1709-1721. 
17. Negi, P.S.; Roy, S.K. Changes in $\beta$-carotene and ascorbic acid content of fresh amaranth and fenugreek leaves during storage by low cost technique. Plant Foods Hum. Nutr. 2004, 58, $225-230$.

18. Tulio, A.Z.; Ose, K.; Chachin, K.; Ueda, Y. Effects of storage temperatures on the postharvest quality of jute leaves (Corchorus oliotorius L.). Postharvest Biol. Technol. 2002, 26, 329-338.

(C) 2015 by the authors; licensee MDPI, Basel, Switzerland. This article is an open access article distributed under the terms and conditions of the Creative Commons Attribution license (http://creativecommons.org/licenses/by/4.0/). 